\title{
DEFORMATION ANALYSIS OF A METROPOLIS FROM C- TO X-BAND PSI: PROOF-OF-CONCEPT WITH COSMO-SKYMED OVER ROME, ITALY
}

\author{
Deodato Tapete $^{(a, b)}$, Francesca Cigna ${ }^{(a, b)}$, Rosa Lasaponara ${ }^{(b)}$, Nicola Masini ${ }^{(c)}$, Pietro Milillo $^{(d)}$ \\ ${ }^{a}$ British Geological Survey, Natural Environment Research Council, UK \\ ${ }^{\mathrm{b}}$ Institute of Methodologies for Environmental Analysis, National Research Council, Italy \\ ${ }^{\mathrm{c}}$ Institute for Archaeological and Monumental Heritage, National Research Council, Italy \\ ${ }^{\mathrm{d}}$ School of Engineering, University of Basilicata, Italy
}

\begin{abstract}
Stability of monuments and subsidence of residential quarters in Rome (Italy) are depicted based on geospatial analysis of more than 310,000 Persistent Scatterers (PS) obtained from Stanford Method for Persistent Scatterers (StaMPS) processing of 32 COSMO-SkyMed 3m-resolution HH StripMap ascending mode scenes acquired between 21 March 2011 and 10 June 2013. COSMO-SkyMed PS densities and associated displacement velocities are compared with almost 20 years of historical C-band ERS$1 / 2$, ENVISAT and RADARSAT-1/2 imagery. Accounting for differences in image processing algorithms and satellite acquisition geometries, we assess the feasibility of ground motion monitoring in big cities and metropolitan areas by coupling newly acquired and legacy SAR in full time series. Limitations and operational benefits of the transition from medium resolution C-band to high resolution X-band PS data are discussed, alongside the potential impact on the management of expanding urban environments.
\end{abstract}

Index Terms - Urban remote sensing, Persistent Scatterer Interferometry, subsidence, ground motion monitoring, Rome

\section{INTRODUCTION}

Two generations of Synthetic Aperture Radar (SAR) satellite missions - from C-band ERS-1/2, ENVISAT ASAR and RADARSAT-1/2 to X-band COSMO-SkyMed and TerraSAR-X - have produced an increasing archive of imagery that, over several big cities and metropolises across the world, provides an almost continuous temporal coverage since the early 1990s. Therefore we can now process newly acquired SAR data with meter-level spatial resolution and up to daily temporal sampling, extract deformation estimates via Differential Interferometric SAR (DInSAR) or Persistent Scatterer Interferometry (PSI), and look retrospectively at both historical and recent deformation. In doing so, we may assess whether the observed motion patterns are due to natural and/or human-induced processes (e.g., ground instability and groundwater abstraction), or if the condition is unaltered.

Rome, central Italy, is an ideal candidate for this type of investigation. It is covered by very long SAR data stacks, for instance, almost 70 ERS-1/2 descending images with repeat cycle of 35 days between 1992 and 2000, and more than 80 RADARSAT-1 images in both ascending and descending geometries acquired every 24 days from 2003 to 2010 [1].

Taking advantage of this time series data, several authors studied subsidence of buildings located in areas of compressible soils $[2,3]$, structural instability triggered by geological hazards (e.g. landslides) and poor maintenance of ancient structures $[4,5,6]$. This research presents evidence of overall stability across the town centre with only localized deformation, whereas subsidence persists in the southern quarters in proximity to the Tiber River.

This paper demonstrates the added value of fullyoperational SAR constellations such as COSMO-SkyMed to extend the temporal observation window of ground and structural stability of a dynamic urban environment. We discuss advantages and limitations of the analysis of deformation estimates from multi-sensor data, to account for the differences in satellite geometries and even in processing algorithms implemented in previous InSAR analyses.

\section{COSMO-SKYMED DATA INPUT AND STAMPS PROCESSING}

To retrieve an updated picture of stability and subsidence across Rome, we analyzed time series data from 32 COSMO-SkyMed StripMap HIMAGE ascending mode scenes with an image swath of $40 \mathrm{~km}, 3-\mathrm{m}$ resolution and $\mathrm{HH}$ polarization. This was acquired in H4_05 Beam mode between 21 March 2011 and 10 June 2013, with repeat cycle mostly equal to 16 days, Line-Of-Sight (LOS) incidence angle of $34^{\circ}$ at the scene centre and track angle of the satellite orbits of $-9^{\circ}$. 

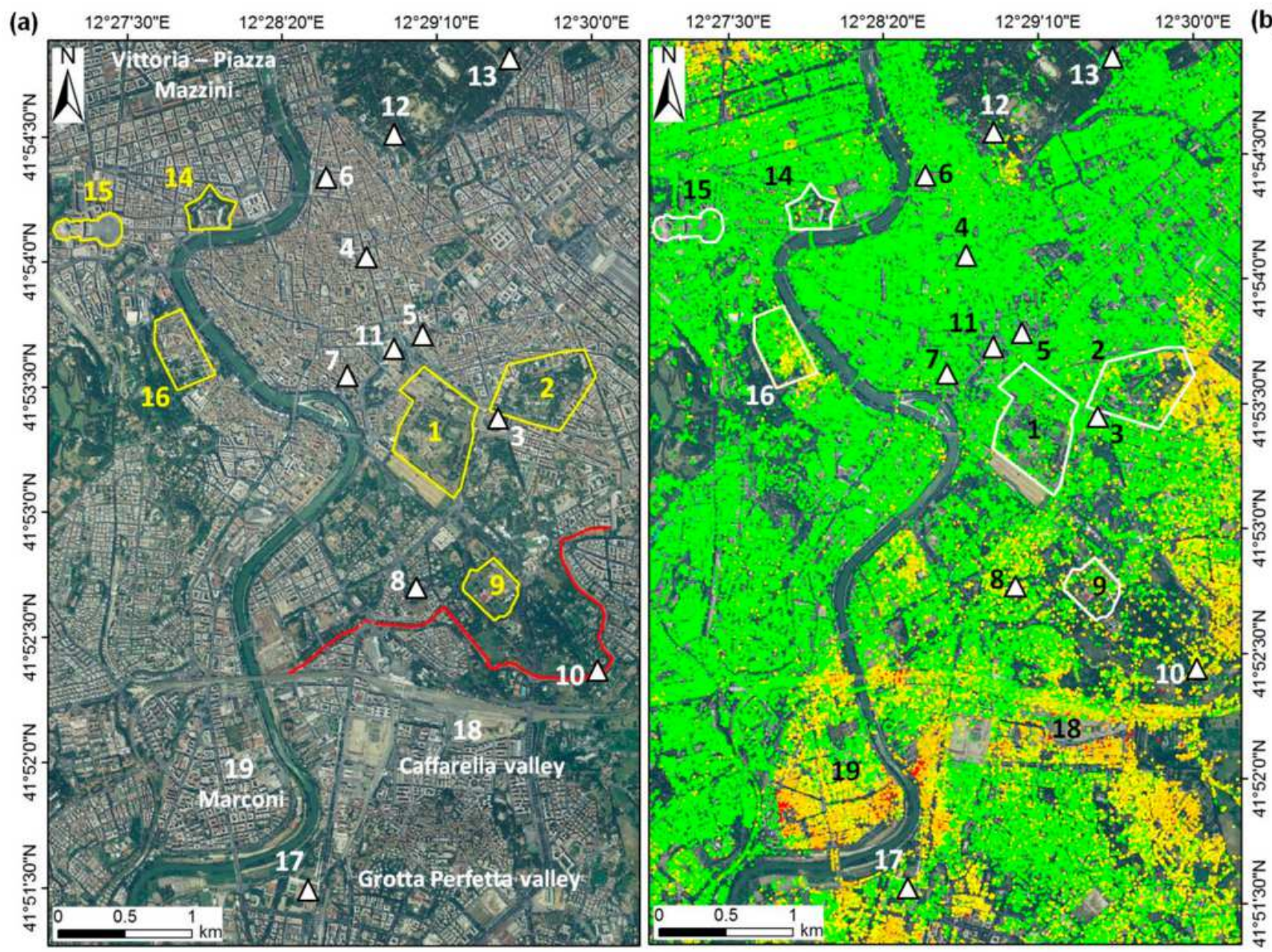

(a) Monuments and sites Aurelian Walls -
Heritage assets $\Delta$ (b) COSMO-SkyMed PS O

$$
\mathrm{V}_{\mathrm{Los}}[\mathrm{mm} / \mathrm{yr}]
$$$$
-7.1--5.0 \square-4.9--3.0 \square-2.9--2.0 \square-1.9-+2.0 \square+2.1-+3.0
$$

Figure 1. (a) Aerial view of the city of Rome and (b) spatial distribution of COSMO-SkyMed StripMap PS (March 2011-June 2013) processed with the StaMPS algorithm [7], with associated $V_{L O S}$. Numbering refers to urban and heritage assets of concern for this research: (1) Palatine Hill and Roman Forum; (2) Oppian Hill, Baths of Trajan and Cisterna delle Sette Sale; (3) Colosseum; (4) Marcus Aurelius' Column; (5) Trajan's Column and Imperial Forums; (6) Mausoleum of Augustus; (7) Porticus Octaviae; (8) Basilica di San Saba; (9) Baths of Caracalla; (10) Porta San Sebastiano and Arch of Drusus; (11) Vittoriano; (12) Villa Medici; (13) Galleria Borghese; (14) Castel Sant'Angelo; (15) Basilica of St. Peter, Vatican; (16) Via delle Mantellate, Trastevere; (17) Basilica of St. Paul Outside the Walls; (18) Caffarella quarter; (19) Marconi quarter.

The orientation of the LOS at the scene centre and computation of its directional cosines suggest that the LOS of the stack is capable of depicting $83 \%$ of vertical motion, $55 \%$ of E-W motions and only $9 \%$ of N-S motions.

PSI processing was undertaken using the single-master PSI approach Stanford Method for Persistent Scatterers (StaMPS), selecting a subset of the full COSMO-SkyMed frame centered at the location $12.485^{\circ} \mathrm{E}, 41.900^{\circ} \mathrm{N}$, with a total extent of $\sim 109 \mathrm{~km}^{2}$ [7]. More than
310,000 radar targets (i.e. PS) were identified, with an average target density of over 2,800 PS/ $\mathrm{km}^{2}$ (Figure 1).

Assuming that land motion occurred mainly along the vertical direction (in the form of either subsidence or ground heave), we divided the LOS values $\left(\mathrm{V}_{\mathrm{LOS}}\right)$ by the directional cosine of the LOS along the vertical direction, i.e., $\cos 34^{\circ}$, hence 0.83 , to derived vertical velocity values $\left(\mathrm{V}_{\mathrm{v}}\right)$. This resulted in the increase of all LOS velocity values by $21 \%$, the COSMO-SkyMed LOS in this mode being capable of depicting $83 \%$ of pure vertical motions. 


\section{DEFORMATION PATTERNS (2011-2013)}

During 2011-2013 the urban area of Rome shows an overall stability with a motion rate, on average, equal to $-1.44 \pm$ $1.56 \mathrm{~mm} /$ year across the whole processing area. Deformation patterns with ground motion velocity mostly in the direction away from the satellite sensor (up to -8.60 $\mathrm{mm} /$ year vertical annual rates) are concentrated over the Grotta Perfetta, Garbatella and Marconi quarters (No. 17-19 in Figure 1), V Nomentano and the Tiburtina station nearby to the east, as well as in Trastevere quarter, on the right riverbank (No. 16 in Figure 1).

As expected according to the theory of ground settlement induced by urbanization [3], the historic centre of Rome including the central archaeological areas of Colosseum, Roman and Imperial Forums, Palatine and Oppian Hills (No.1-3 in Figure 1) appears relatively stable at a small-scale view. Whereas, investigation of PS clusters over single buildings reveals local structural deformation affecting some of the archaeological ruins belonging to the Baths of Trajan within the Oppian Hill park (No. 2 in Figure 1), as well as a clear deformation pattern over the medieval complex of Basilica di San Saba (No. 8 in Figure 1) with an average $\mathrm{V}_{\mathrm{v}}$ of $-2.3 \mathrm{~mm} / \mathrm{year}$ and values up to $-5.3 \mathrm{~mm} / \mathrm{year}$.

\section{MULTI-TEMPORAL COMPARISON WITH C- BAND PSI AND KEY REMARKS}

Local vegetation cover, visibility of the building structure to the satellite geometry, and the rationale of the InSAR processing chain implemented, are the main factors constraining the comparative assessment between recent $\mathrm{X}$ and historical C-band PSI data.

Owing to thousands of radar targets identified, 130 of which fall over the architectural complex of Basilica of St Paul Outside the Walls (No.17 in Figure 1; Figure 2), we are able to confirm the persistence of subsidence-related deformation $\left(\mathrm{V}_{\mathrm{v}}\right.$ up to $-8.6 \mathrm{~mm} / \mathrm{year}$, average -3.0 $\mathrm{mm} /$ year). Spatial patterns and deformation rates are in agreement with Small BAseline Subset - SBAS [2,5] and Interferometric Point Target Analysis - IPTA processing [3] of ERS-1/2 and ENVISAT time series from 1992 to 2010. However, the COSMO-SkyMed ascending geometry and related incidence angles seem to have affected results over north-facing steep slopes such as the western side of the Palatine Hill and the Domus Tiberiana located at its NNW corner (No.1 in Figure 1). The scarcity of PS in this case prevented any deformation analysis to be performed, though previous research [1] proved the feasibility of multi-sensor approach from PSInSAR ${ }^{\mathrm{TM}}$ ERS-1/2 descending to RADARSAT- 1 ascending PSI data.
The influence of the InSAR processing chain has been instead observed over the Roman cistern, known as Cisterna delle Sette Sale, in the NE corner of the Oppian Hill park (No.2 in Figure 1). Compared with the higher PS density obtained with the RADARSAT-1 ascending SqueeSAR ${ }^{\text {TM }}$ data published in $[1,4]$, the COSMO-SkyMed dataset (20112013) offers only two PS, localized over the SW corner of the cistern $\left(\mathrm{V}_{\mathrm{v}}\right.$ of -3.7 and $\left.-3.1 \mathrm{~mm} / \mathrm{year}\right)$. The different nature of radar targets considered by the StaMPS routine with respect to SqueeSAR ${ }^{\mathrm{TM}}$ is one of the key factors that can explain such a diverse performance over the same monument, although we expected the retrieval of a higher PS density owing to the higher spatial resolution of the COSMO-SkyMed imagery. Notwithstanding, it is noted that the two COSMO-SkyMed PS show similar magnitude and spatial distribution of the deformation detected in 20032010 , reinforcing warnings of local structural instability.

These examples demonstrate the limitations and operational benefits when exploiting current SAR satellites for near-continuous ground motion time series from previous missions. Unless the same processing algorithm is used, this difference should be accounted for among the variables.

\section{CONCLUSIONS}

Our geospatial analysis of COSMO-SkyMed PS data (20112013) highlighted deformation patterns that align with those observed in Rome in the last 20 years:

(i) Overall stability of the key monuments is observed, except for Trastevere and Basilica di San Saba;

(ii) Persistent subsidence with $\mathrm{V}_{\mathrm{v}}$ of more than -7.0 $\mathrm{mm} /$ year occurs in areas of recent urbanization, i.e. Marconi quarter, Caffarella and Grotta Perfetta valleys.

Such confirmation demonstrates the value and reliability of continuous InSAR monitoring to assess and understand the trends of geohazard processes, associated with ground movement in expanding urban environments.

\section{ACKNOWLEDGEMENTS}

This research was performed in the framework of the project "Smart management of cultural heritage sites in Italy and China: Earth observation and pilot projects", funded by the Italian Ministry of Foreign Affairs. COSMO-SkyMed data were provided by the Italian Space Agency, under license agreement Archeocosmo. SRTM DEM data were provided by NASA via the Consultative Group for International Agriculture Research - Consortium for Spatial Information, CGIAR-CSI (http://srtm.csi.cgiar.org). The 2008 orthophoto was accessed via the WMS service of the National Geoportal of the Italian Ministry of Environment, Land and Sea. 


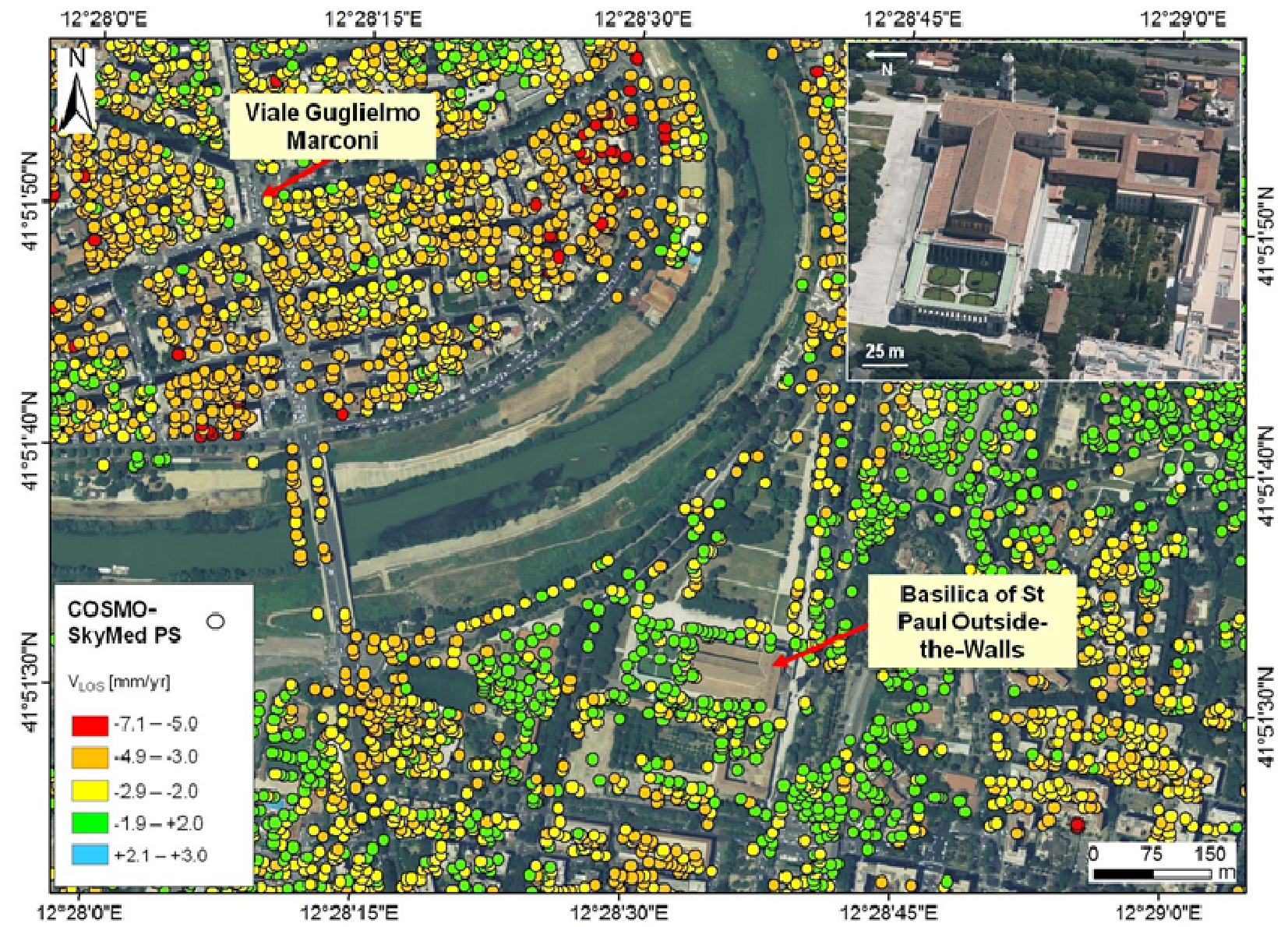

Figure 2. VLOS of the COSMO-SkyMed PS over the architectural complex of the Basilica of St. Paul Outside the Walls and the Marconi quarter (i.e., Nos. 17 and 19 in Figure 1) [7]. The inset shows an aerial photograph of the basilica from BingMaps (@ 2014 BLOM, @ 2014 Microsoft Company).

\section{REFERENCES}

[1] D. Tapete, R. Fanti, R. Cecchi, P. Petrangeli, and N. Casagli, "Satellite radar interferometry for monitoring and early-stage warning of structural instability in archaeological sites," Journal of Geophysics and Engineering, IOPScience, pp. S10-S25, 2012.

[2] M. Manunta, M. Marsella, G. Zeni, M. Sciotti, S. Atzori, and R. Lanari, "Two-scale surface deformation analysis using the SBAS-DInSAR technique: A case study of the city of Rome, Italy”, International Journal of Remote Sensing, Taylor \& Francis, pp. 1665-1684, 2008.

[3] S. Stramondo, F. Bozzano, F. Marra, U. Wegmuller, F.R. Cinti, M. Moro, and M. Saroli, "Subsidence induced by urbanisation in the city of Rome detected by advanced InSAR technique and geotechnical investigations," Remote Sensing of Environment, Elsevier, pp. 3160-3172, 2008.

[4] D. Tapete, N. Casagli, and R. Fanti, Radar interferometry for early stage warning on monuments at risk. In: Landslide Science and Practice; Margottini, C., Canuti, P., Sassa, K., Eds., Springer, Berlin/Heidelberg, Germany, pp. 619-625, 2013.

[5] G. Zeni, M. Bonano, F. Casu, M. Manunta, M. Manzo, M. Marsella, M. Pepe, and R. Lanari, "Long-term deformation analysis of historical buildings through the advanced SBASDInSAR technique: The case study of the city of Rome, Italy," Journal of Geophysics and Engineering, IOPScience, pp. S1-S12, 2011.

[6] D. Tapete, S. Morelli, R. Fanti, and N. Casagli, "Localising deformation along the elevation of linear structures: An experiment with space-borne InSAR and RTK GPS on the Roman Aqueducts in Rome, Italy," Applied Geography, Elsevier, pp. 65-83, 2015.

[7] F. Cigna, R. Lasaponara, N. Masini, P. Milillo, and D. Tapete, "Persistent Scatterer Interferometry Processing of COSMOSkyMed StripMap HIMAGE Time Series to Depict Deformation of the Historic Centre of Rome, Italy," Remote Sensing, MDPI, pp. 12593-12618, 2014. 